Stallworthy, J. S. (1950). Transactions of the American Association of Obstetricians, Gynecologists and Abdominal Surgeons, 61, 9.

Stern, H. S., Goodwin, D. A., Scheffel, U., Wagner, H. N., and Kramer, H. H. (1967). Nucleonics, 25, No. 2, p. 62.

Sutton, D. (1966). British fournal of Radiology, 39, 47.
Vickers, A. A. (1965). Clinical Radiology, 16, 351.

Wagner, H. N. (editor) (1968). Principles of Nuclear Medicine. Philadelphia, Saunders.

Wright, F. W. (1969). British fournal of Radiology, 42, 475.

Wright, F. W., Merrick, M. V., Holt, M., and Oliver, R. (1969). British fournal of Radiology, 42, 235.

\title{
Miosis during L-Dopa Therapy
}
A. S. D. SPIERS, ${ }^{*}$ M.B., PH.D., M.R.A.C.P. ;
D. B. CALNE, $†$ D.M., M.R.C.P. ;
P. M. FAYERS, $\ddagger$ B.SC.

British Medical fournal, 1970, 2, 639-640

Gummary: The pupillary diameter of 11 patients $\checkmark$ with Parkinson's disease was significantly decreased four hours after ingestion of L-dopa. It is suggested that this miosis may be caused by diminished noradrenaline output at sympathetic nerve endings, or alternatively by an action on the central nervous system.

\section{Introduction}

L-Dopa produces improvement in the manifestations of Parkinsonism and has an important therapeutic role in this common condition (Cotzias et al, 1968, 1969; Yahr et al., 1968, 1969; Calne et al., 1969a, 1969b; Godwin-Austen et al., 1969b). Both hypertension and, more commonly, hypotension may occur during L-dopa therapy (Cotzias et al., 1968, 1969; Yahr et al., 1968, 1969; Calne et al., 1970). The most likely explanation of these observations is that L-dopa therapy interferes with sympathetic activity, which in turn leads to hypotension, particularly in the erect posture.

We have investigated the pupillary aperture in patients during and after L-dopa therapy as a convenient measure of peripheral sympathetic activity.

\section{Patients and Methods}

Eleven patients participating in a trial of L-dopa therapy in idiopathic Parkinsonism (Calne et al., 1969b) were studied. Their ages ranged from 47 to 65 years and their initial Parkinsonian symptoms varied from mild to gross disability. The daily doses of L-dopa ranged from 1.0 to $6.8 \mathrm{~g}$. (mean 3.2 g.). For each patient an ocular photograph was taken during maintenance with maximum tolerated doses of L-dopa. Photographs were taken at 12.30 p.m., four hours after the most recent dose of L-dopa. The second series of photographs was made several weeks after ceasing L-dopa therapy.

To ensure constant lighting and to minimize the effects of tremor the head rest and lighting system of a Leitz slit-lamp were used. Measured light intensities were reproduced between series of photographs. Photographs were taken with an Exakta Varex IIB 35-mm. camera, a Trioplan $10-\mathrm{cm}$. lens with focusing bellows and Ilford HP4 film being used. The back of the camera was $40 \mathrm{~cm}$. from the bridge of the subject's nose. To avoid the effects of accommodation, patients looked "through" the camera lens without focusing. Three photographs were made on each occasion and negatives were projected on to the wall of a darkroom, giving a final magnification of $\times 15$. Measurements of the horizontal diameter of the pupil were made. Observations were performed on the left eye: all three photographs in each patient were used and the mean of the readings was taken.

* Nuffield Dominion Travelling Fellow, University College Hospital, London W.C.1. Present address: Hammersmith Hospital, Du Cane Load, London W.12.

† Wellcome Fellow in Clinical Pharmacology, University College Hospital, London W.C.1. At present Lecturer in Neurology, Hammersmith Hospital, London W.12.

¥ Medical Research Council Statistical Research and Services Unit, London W.C.1.

\section{Results}

Variations in pupillary diameter within each set of three photographs were small (often less than $1 \mathrm{~mm}$. on the magnified image), suggesting that fluctuations in accommodation were not affecting results.

Pupillary diameters during and after L-dopa therapy, and the percentage differences for each patient, are set out in the Table. In 10 of the 11 patients the pupil was smaller during L-dopa therapy than after its cessation. A Wilcoxon signed rank test showed that the difference in pupillary diameters is significant at the $0.1 \%$ level.

The extent of miosis in individual patients showed no correlation with the dose of L-dopa, the development of hypotension, or the response of the Parkinsonism to therapy. There was a similar lack of correlation between dose, hypotension, and therapeutic response.

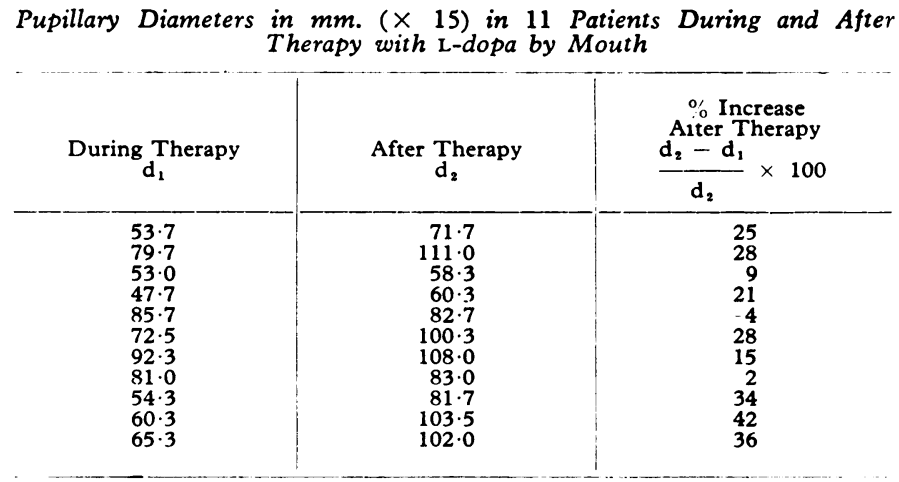

\section{Discussion}

The finding of a significant miosis during L-dopa therapy is compatible with the hypothesis that sympathetic tone is reduced by this treatment. The demonstration of orthostatic hypotension during L-dopa therapy also accords well with this view. Reduced sympathetic activity during therapy with a drug which is a precursor of noradrenaline may appear paradoxical. It has been shown, however, that both dopamine (Spiers and Calne, 1969) and L-dopa (Calne and Spiers, 1970) cause release of noradrenaline from sympathetic nerve endings, and may produce depletion of noradrenaline stores, even though both drugs are precursors of noradrenaline. That amine release by dopamine may outstrip synthesis has been shown in animal experiments (Harrison et al., 1963; Eränkö and Räisänen, 1968). Administration of L-dopa restores the noradrenaline content of peripheral adrenergic nerves after reduction by reserpine (Pennefather and Rand, 1960), but apparently does not increase peripheral noradrenaline stores when these are initially normal. Though treatment with Ldopa increases the dopamine oontent of rabbit brain, changes in noradrenaline levels are slight or absent (Carlsson et al., 1958).

During long-term therapy with L-dopa by mcuth pupillary dilatation has sometimes been observed one to two hours after an oral dose of L-dopa (van Woert, personal commu- 
nication, 1969). Many of our patients report an awakening reaction shortly after taking L-dopa, with symptoms resembling those following ingestion of amphetamine. These observations are compatible with the view that L-dopa causes release of amines from adrenergic nerve endings. The significant miosis we have observed with continuous oral $\mathrm{L}$ dopa therapy, like the hypotension, may reflect decreased peripheral sympathetic activity following noradrenaline depletion at sympathetic nerve endings. Since the drug causing depletion is itself a noradrenaline precursor such depletion might be only partial. This expectation is confirmed by the finding (Godwin-Austen et al., 1969a) that patients treated with L-dopa still show a mydriatic response to tyramine, which acts by releasing noradrenaline from nerve endings in the iris.

Diminished mydriasis with phenylephrine reported during L-dopa therapy has been attributed to $\alpha$-adrenergic receptor blockade by L-dopa or its metabolites (GodwinAusten et al., 1969a). A brisk mydriatic response to phenylephrine drops, however, still occurs in eyes treated with high concentrations of dopamine or L-dopa for several hours (Spiers and Calne, 1969; Calne and Spiers, 1970). Since prolonged application of high concentrations of a drug is a sensitive test for blocking activity, it seems unlikely that dopamine or L-dopa produces significant $\alpha$-blockade.

Miosis is not always detectable during L-dopa therapy; no change in resting pupillary size was detected in one series of 18 patients (Godwin-Austen et al., 1969a). Absence of miosis in these patients might be due to short duration of L-dopa therapy (Spiers, 1969) or to the timing of ocular photography. If this was done shortly after a dose of L-dopa the acute mydriatic effects of the drug, due to amine release, would mask the underlying chronic miosis, due to partial amine depletion. Timing of observations may well explain the occasional observation of hypertension instead of hypotension during L-dopa therapy, for intravenous administration of Ldopa to man produces an acute hypertensive response (Degkwitz, et al., 1960) which accords well with its acute mydriatic effects.

The effect of L-dopa and dopamine on adrenergic nerve endings may be more complex than simple noradrenaline depletion. Collins and West (1968) showed that incubation of rabbit ileum with dopamine or L-dopa leads to accumulation of dopamine within the sympathetic nerve terminals, and subsequent stimulation of the nerves releases dopamine. Burn (personal communication, 1969), suggested that in patients receiving L-dopa nerve impulses may release a normal amount of total catecholamines, but much of this will be dopamine, so the quantity of noradrenaline released by each impulse will be subnormal. Since dopamine has less capacity than noradrenaline to stimulate $\alpha$-adrenergic receptors (Goldberg et al., 1969), the effects of sympathetic nerve impulses will be diluted. Under these circumstances hypotension, miosis, and perhaps a reduced cardiac response to exercise are possible clinical results of L-dopa therapy.

An alternative explanation of all these observations is that L-dopa exerts its sympatholytic action centrally, possibly by modulating levels of brain amines.

We are indebted to the departments of medical photography, in particular Mr. R. Strutt, and medical illustration, University College Hospital Medical School. Professor D. R. Laurence gave helpful advice and discussion.

\section{REFERENCES}

Calne, D. B., Stern, G. M., Laurence, D. R., Sharkey, J., and Armitage, P. (1969a). Lancet, 1, 744.

Calne, D. B., Spiers, A. S. D., Stern, G. M., Laurence, D. R., and Armitage, P. (1969b) Lancet, 2, 973

Calne, D. B., Brennan, J., Spiers, A. S. D., and Stern, G. M. (1970) British Medical fournal, 1, 474.

Calne, D. B., and Spiers, A. S. D. (1970). Contemporary Neurology. In

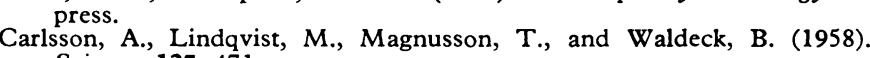
Science, 127, 471 .

Collins, G. G. S., and West, G. B. (1968). British fournal of Pharmacology, 34, 514.

Cotzias, G. C., Papavasiliou, P. S., Gellene, R., and Aronson, R. B. (1968). Transactions of the Association of American Physicians, 81, 171.

Cotzias, G. C., Papavasiliou, P. S., and Gellene, R. (1969). New England Fournal of Medicine, 280, 337.

Degkwitz, R., Frowein, R., Kulcnkampff, C., and Mohs, U. (1960). Klinische Wochenschrift, 38, 120.

Eränkö, O., and Räisänen, L. (1968). Mechanisms of Release of Biogenic Amines, ed. U. S. Von Euler, S. Rossell, and B. Uvnäs, p. 73. London, Pergamon.

Godwin-Austen, R. B., Lind, N. A., and Turner, P. (1969a). Lancet, $2,1043$.

Godwin-Austen, R. B., Tomlinson, E. B., Frears, C. C., and Kok, H. W. L.' (1969b). Lancet, 2, 165

Goldberg, L. I., Talley, R. C., and McNay, J. L. (1969). Progress in Cardiovascular Diseases, 12, 40.

Harrison, W. H., Levitt, M., and Udenfriend, S. (1963). Fournal of Pharmacology and Experimental Therapeutics, 142, 157.

Pennefather, J. N., and Rand, M. J. (1960). Fournal of Physiology, 154, 277.

Spiers, A. S. D. (1969). Lancet, 2, 1301

Spiers, A. S. D., and Calne, D. B. (1969) British Medical fournal, 4 333.

Yahr, M. D., Duvoisin, R. C., Hoehn, M. M., Schear, M. J., and Barrett, R. E. (1968). Transactions of the American Neurological Association, 93, 56.

Yahr, M. D., Duvoisin, R. C., Schear, M. J., Barrett, R. E., and Hoehn, M. M. (1969). Archives of Neurology, 21, 343.

\title{
Eroded Cervix
}

\author{
UNA M. KROLL, ${ }^{*}$ M.B., B.CHIR., M.R.C.G.P.
}

$S^{n}$ ummary: During a six-year period 1,808 women aged 20 to 59 underwent gynaecological examination at a well-woman clinic. Cervical erosions were found in 269. Nine patients had cervical carcinoma, confirmed by biopsy; of these eight had eroded cervices. The remaining patients with non-malignant erosions were examined at six-monthly intervals. Of these, roughly $39 \%$ showed spontaneous healing within a year, $31 \%$ responded to medical treatment, $17 \%$ healed only after surgical treatment, $9 \%$ remained unhealed when reviewed six months after the last active treatment, and $4 \%$ relapsed after originally healing well.

The difficulties of getting patients to return for cytological examination increase with the interval between the original examination and recall. It is suggested that

* General Practitioner, St. Paul's Cray, Kent. patients should be re-examined initially at an interval not exceeding six months, so that false negative results are minimal.

\section{Introduction}

The value of cervical cytology in the diagnosis of carcinoma of the uterine cervix is now well established. Its practical application has been shown among patients attending hospital (Yule and Cameron, 1961), local authority clinics (Jones and Metcalfe Brown, 1965), and general practice clinics (MacGregor and Baird, 1963). The relation of carcinoma to other abnormalities of the uterine cervix is also well documented. Stoll (1958), in a review of 16,749 patients, found the incidence of carcinoma in clinically eroded cervices to be 26 times more common than in clinically normal cervices. In his survey the incidence of all types of carcinoma was $1: 1,345$ in macrosco- 